УДК 81.366.512.141

DOI: 10.33184 /bulletin-bsu-2020.2.36

ЭМПОРОНИМЫ ГОРОДА СТЕРЛИТАМАК

\author{
(C) Г. Р. Фазылова, М. И. Карабаев*, Г. Р. Абдуллина \\ Башкирский государственный университет \\ Россия, Республика Башкортостан, 450076 г. Уфа, ул. Заки Валиди, 32. \\ Тел./факс: +7 (347) 2723382. \\ *Email: munir.karabaev@yandex.ru
}

\begin{abstract}
Научная статья посвящуена изучению одного из ичентральных единиц современной урбанонимии - эмпоронимов. Целью работы является комплексный анализ эмпоронимов, то есть с точки зрения выполнения ими функиий, а также в статье решаются такие задачи, как определение роли выявление участия частей речи в образовании эмпоронимов, определение способов словообразования в наименованиях торговых объектов, описание проиесса трансонимизации в образовании эмпоронимов. В ономастических исследованиях целенаправленно развивается направление, которое ориентировано на исследование наименований городских объектов урбанонимов. Эмпоронимы, будучи наиболее важным элементом урбанонимии, представляют интерес для лингвистов не только в качестве языковой единиць, но и как выражение сочиально-культурных явлений. Эмпоронимам характерны частые изменения, они более подвижны по сравнению с другими наименованиями городских объектов. По лексико-грамматическому признаку можно утверждать, что в функиии наименования торгового учреждения могут выступать все знаменательные части речи. Кроме идентификационно-дифферениирующей функции эмпоронимы выполняют информационную и рекламную функции.
\end{abstract}

Ключевые слова: башкирский язык, ономастика, урбаноним, эмпороним, номинация.

В последние десятилетия в современной ономастике наблюдается определенная активность в исследовании по выявлению лингвистических и экстралингвистических особенностей наименований городских объектов [19-20]. В результате изысканий ученых-лингвистов утвердилась собственная терминология в области изучения городского ономастикона. Для обозначения объектов данной группы в лингвистике принято использовать термин «урбаноним», который определятся как «вид топонима», «собственное имя любого внутригородского топографического объекта...» [12].

Урбанонимы могут быть наименованиями как коммерческих, так и некоммерческих объектов, поэтому они находятся в контакте с коммерческой номинацией, но не включены в нее полностью. К урбанонимам относятся экодомонимы - собственные имена любых зданий. К коммерческой номинации можно отнести эмпоронимы (названия торговых предприятий), рекламные названия и названия компаний. По Т. В. Шмелевой, термин «эмпороним» обозначает наименования торговых учреждений, а также названия других учреждений, связанных с коммерческой деятельностью [23].

Как и вся языковая система, эмпоронимия каждого города подвергается изменениям, но, в отличие от других систем, данное явление в урбанонимическом пространстве происходит часто и намного быстрее.

В качестве ономастической единицы эмпороним выполняет общую функцию данного класса имен, идентификационно-дифференцирующую: он служит для наименования городских объектов и выделяет их из цикла таких же.
Если говорить о частях речи, которые выступают в качестве эмпоронимов, то в данном случае, можно констатировать, что любая знаменательная часть речи может выполнять функцию эмпоронима (имя существительное, имя прилагательное, имя числительное, глагол, наречие, местоимение) в результате перехода из одной категории в другую.

Эмпоронимы имеют ряд признаков, которые отличают их от других онимов:

а) в структурно-семантическом плане в качестве эмпоронимов может выступать любой элемент языка - от отдельного графического оформления до полного предложения;

б) в структуре данного типа онимов часто наблюдаются изменения, исключения способов образования эмпоронимов не отображаются в общем восприятии. Так же как и всем ономастическим единицам, эмпоронимам характерна классификационная система нарицательных имен;

в) недолговременность и неустойчивость.

Существуют определенные трудности в исследовании закономерностей в номинации эмпоронимов. Лингвисты в этом случае предлагают использовать термин «вторичная номинация» и «третичная номинация». К третичной номинации относят создание эмпоронимов на основе других онимов, в некоторых случаях наименованиями торговых объектов становятся товарные знаки [10]. Кроме того, ученые выделяют естественную номинацию и искусственную номинацию.

Лингвисты считают, что искусственная номинация связана с осознанной деятельностью человека и является рациональным действием, направленным на достижение конкретной цели [17]. 
Переходим к рассмотрению эмпоронимов как неотъемлемой части урбанонимической системы Стерлитамака. При классификации эмпоронимов города выделяются несколько крупных лексикосемантических групп. Первую тематическую группу можно классифицировать по выполняемым им функциям. Как известно, главная функция ономастических единиц - номинативная, в этом случае наблюдается идентификация объекта; оним выделяет данный объект среди других таких же предметов и не несет никакой информации. К таким наименованиям можно отнести следующие эмпоронимы: Хобби, Регион, Усолье, Светофор, Лента.

Большая часть эмпоронимов выполняет функцию рекламы. В этом случае при выборе наименования ставится главная цель - это привлечение внимания покупателей. Данные единицы несут положительную оценку. Например: Модная семейка, Elegant, Комплимент, Эксклюзив+.

В наименованиях торговых предприятий можно встретить названия предлагаемых покупателям товаров. Такие онимы входят в группу эмпоронимов, которые выполняют информативную функцию. Содержание информации может быть двух типов: рекламная и рациональная. Рациональная информация важна не только для продавца, но и для покупателя. Здесь дается определенная информация об объекте продажи: Рыбная лавка, Мир Жалюзи, Деталь, Автосвет, Магазин автозапчастей для Toyota Lexus, Шубный, Хлебный, Книги, Чайный домик, Продуктовый магазин, Строй крепеж, СтройМонтаж, Цветы от Венеры, Пельмени от Елены, Славянский текстиль.

В рекламной информации содержится оценочная характеристика: Мясной король, Мир Жалюзи, Магия пряжи, Чудеса из шаров.

Информативно-рекламная функция эмпоронимов информирует об объекте продажи и одновременно дает положительную оценку предприятию [16]. Данная функция ярко проявляется в наименованиях следующих магазинов Стерлитамака: Чистый Вкус, Мебель ТУТ Дешевле, Мебель даром, Дешевые Колеса, Смешные иены. Таким образом, функциональная классификация эмпоронимов имеет практическую направленность и связана с реализацией товаров и услуг.

Как и любые языковые единицы, эмпоронимы классифируются по способу словообразования [1]. В эмпоронимии Стерлитамака можно выделить следующие типы номинаций по способу словообразования:

1) эмпоронимы, образованные способом конверсии, то есть в результате перехода из одной лексико-грамматической группы в другую: Народныц̆, Хлебныци, Шубный;

2) сложение основ; данный способ образования является продуктивным способом пополнения состава эмпоронимов: Электромаркет, Электроград, Евросеть, Фитоцентр, СтройМонтаж,
Башспирт. В эту же группу можно отнести сложные слова, у которых наблюдается усечение словообразующих основ: Франсавт;

3) эмпоронимы, образованные способом аббревиации: $M T C, S G, D N S$.

В некоторых случаях соединение двух основ сложного наименования происходит при помощи дефиса: Кубик-рубик, ИДЕЛЬ-МЕБЕЛЬ, Арmтекстиль.

В образовании наименований торговых объектов Стерлитамака используются и другие способы словообразования. При лексико-семантическом словообразовании сохраняются формальные показатели лексической единицы, изменение наблюдается в содержании. Данный факт можно встретить в следующих наименованиях: Сказка, Дворик, Премьер, Молоток, Серенада, Дружба.

Лексико-синтаксический способ предполагает переход в состав лексической единицы словосочетания или целого предложения. Такой способ образования эмпоронимов довольно распространенное явление в урбанонимии города Стерлитамак. В результате данного процесса образованы следующие наименования: Бравый моряк, Твой имидж, Верный Мастер, Фабрика праздников 12 месяцев, Пельмени от Елены, Продукты от Акулины, Магазин экономной мебели, Охота и рыбалка, Серебряный дождь.

В процессе образования наименований наблюдаются внутренние ономастические явления, то есть отдельные онимы из одного разряда переходят в другой. Заметную активность в этом процессе проявляют антропонимы [4]. Они в качестве компонента сложного слова или самостоятельно переходят в состав урбанонимов. По мнению лингвистов, в функции словообразовательной основы выступают в большинстве случаев личные имена, а краткие формы имен используются существенно реже полных вариантов. В состав эмпоронимов в основном переходят женские имена, а мужские имена, фамилии и отчества встречаются единично[8]. Примеры отантропонимных эмпоронимов Стерлитамака: а) факты отдельного, самостоятельного перехода: Василиса, Венера, Gulinur, Елена, Милана, Карине; б) случаи трансонимизации в сочетаниях слов: Пельмени от Елены, Цветы от Венеры, Татьянин день. Примеры перехода в разряд эмпоронимов фамилий и мужских имен: Куединский, Ильнур, Максим.

Часто наблюдается трансономизация мифонимов в разряд других единиц ономастики. Данное явление характерно и для урбанонимии. Примеры трансонимизации мифонимов в эмпоронимы: $A л-$ лат, Афродита, Атлант.

В образовании наименований магазинов способом трансонимизации участвуют топонимы. В разряд эмпоронимов могут переходить как макротопонимы, так и микротопонимы: Аркаим, Тавакан, 
Булгар Иле 'Булгария', Евросеть, Урал, Niagara, Эмеральд, Эллада.

В качестве базы для эмпоронимов могут использоваться лексемы разных лексико-семантических групп. Часто номинаторы используют слова, вызывающие определенные ассоциации. К таким наименованиям можно отнести эмпоронимы, в которых присутствуют имена персонажей фильмов, сказок и т.д.: Ваша Фея, Винни Пух. Есть пример использования в функции эмпоронима фразы из кинофильма: Нофелет.

Географические термины являются продуктивными основами для онимизации разных объектов действительности [5]. Особенно ярко данный факт проявляется в топонимии, в т.ч. и в урбанонимическом пространстве. Некоторые географические термины переходят в разряд имен собственных в качестве эмпоронимов: Родник, Лагуна, Усолье.

В составных наименованиях в качестве компонента встречаются этнонимы: Китайский квартал, Русский Свет, Славянский текстиль.

Изучение эмпоронимии города Стерлитамак позволяет нам сделать определенные выводы. Данные наименования являются результатом индивидуального творчества, но нельзя отрицать здесь и коллективное начало. Анализ процесса номинации торговых объектов показывает, что нет системных правил, регламентирующих создание наименований торговых учреждений. Образование новых наименований реализуется при помощи основных словообразовательных способов, в т.ч. и конверсии, появление эмпоронимов включает в себя и трансонимизацию.

\section{ЛИТЕРАТУРА}

1. Alfis Gayazov, Gulfira Abdullina, Flyuza Fatkullina, Guzaliya Ilyasova. Pan-Turkic ergonyms as a linguocultural and sociocultural phenomenon of the Republic of Bashkortostan // Advances in Engineering Research, volume 191. Pp. 66-69.

2. Karabaev M. I., Abdullina G. R., Ishkildina Z. K. Bashkir onomatology in the light of modern linguistics // Mediterranean journal of social sciences. Rome-Italy, MCSER Publishing. 2015. Vol 6. №3 S3. May. Pp. 73-82.

3. Tektigul Zh. O., Sadirova K. K., Kussanova B. H., Zhuminova A. B., Shetiyeva A. T. and Karabaev M. I. Cultural and historical features of kazakh anthroponyms // Modern Journal of Language Teaching Methods, Vol. 7, Issue 11, November. 2017. Pp.185-191.

4. Асанов А. Ю. Урбанонимия города Тамбова в лингвокогнитивном аспекте: дисс. ... канд. филол. наук. Тамбов, 2014. $184 \mathrm{c}$.
5. Абдуллина Г. Р., Абдуллина Л. Б., Султанова М. Р. Прагматический аспект лексических трансформаций при переводе (на мат-ле башк. и англ. языков) // Современные проблемы преподавания башкирского языка как родного и государственного в Республике Башкортостан и других регионах Российской Федерации: мат-лы IV Bcероссийской (с междунар. участием) научно-метод. конф., посвященной 100-летию образования Башкирской АССР и 110-летию Башкирского государственного университета (г. Уфа, 15 февраля 2019 г.). Уфа: РИЦ БашГУ, 2019. С. 5-9.

6. Бондалетов В. Д. Русская ономастика. М.: Просвещение, 1983. $224 \mathrm{c}$

7. Голомидова М. В. Искусственная номинация в ономастике. Екатеринбург, 1998. 232 с.

8. Долганова А. Ю. Процессы трансонимизации в эргономии (на мат-ле названий магазинов Ижевска) // Вестник Удмуртского ун-та. Филол. науки. 2006. №5(2). С. 25.

9. Качалкова Ю. А. Урбанонимическое пространство современного Екатеринбурга (официальные названия) // Вопросы ономастики. 2013. №1. С. 88-103.

10. Кадоло Т. А. Разновидности и способы номинации в наименованиях торговых объектов города Абакана // Известия Саратовского университета. Сер. Филология. Журналистика. 2015. №3.

11. Карабаев М. И. Башкорт ономастикаһы: укыу кулланмаһы. Өфө: БДУ, 2015. 176 б.

12. Подольская Н. В. Словарь русской ономастической терминологии. 2-е изд., перераб. и доп. М.: Наука, 1988. 187 c.

13. Разумов Р. В. Географические термины в системах урбанонимов провинциальных городов // Вопросы ономастики. 2010. №2(9). С. 95-100.

14. Разумов Р. В. Об упорядочении ономастической терминологии в области урбанонимии // Верхневолжский филол. вестник. 2015. №2. С. 14-19.

15. Романова Т. П. Проблемы современной эргонимии / Т. П. Романов // Вестник Самарского гос. ун-та. Сер. «Филология» М. 2008. №1.

16. Романова Т. П. Проблемы современной эргонимии // Вестник Самарского гос. ун-та. Сер. «Филология». 1998. №1.

17. Сологуб О. О взаимодействии искусственного и естественного начал в сфере официально-делового общения (к вопросу об антиномическом устройстве официально-делового языка // Вестник Томского гос. унта, 2009. №3(7). C. 51.

18. Суперанская А. В. Общая теория имени собственного. М.: Наука, 1973. 368 c.

19. Фазылова Г. Р., Абдуллина Г. Р. Названия первых улиц Стерлитамака (лингвистический анализ) // Вестник БашГУ. 2019. Т. 24. №1. C. 155-158. DOI: https://doi.org/ 10.33184/bulletin-bsu-2019.1.26.

20. Фазылова Г. Р., Карабаев М. И. Отантропонимические годонимы города Стерлитамак // Вестник БашГУ. 2019. Т. 24. №4. DOI: https://doi.org/10.33184/bulletin-bsu-2019.4.36.

21. Фазылова Г. Р. Урбанонимическое пространство Стерлитамака // Инновационная наука. Уфа, 2016. №4. Ч. 4. С. 110-112.

22. Шмелева Т. В. Ономастика: учебное пособие. Славянскна-Кубани: Издательский центр филиала ФГБОУ ВПО «КубГУ», 2013. $161 \mathrm{c}$.

23. Шмелева Т. В. Язык города. Наименования магазинов. Красноярск: Красноярский ун-т, 1989. 40 с.

Поступила в редакциию 30.04.2020 2. 
DOI: 10.33184/bulletin-bsu-2020.2.36

\title{
EMPORONYMS OF STERLITAMAK
}

\author{
(C) G. R. Fazylova, M. I. Karabaev*, G. R. Abdullina
}

\author{
Bashkir State University \\ 32 Zaki Validi Street, 450076 Ufa, Republic of Bashkortostan, Russia.
}

Phone: +7 (347) 2723382.

*Email: munir.karabaev@yandex.ru

The article is devoted to the study of one of the central units of modern urbanonymy, emporonyms. The aim of the work is a comprehensive analysis of emporonyms from the point of view of performing their functions; the article also solves such problems as determining the role of revealing the participation of parts of speech in the formation of emporonyms, determining ways of word formation in the names of trade institutions, describing the process of transonymization in the formation of emporonyms. In onomastic studies, a direction will be deliberately developed that is focused on the study of the names of urban objects - urbanonyms. Emporonyms, being the most important element of urbanonymy, are of interest to linguists not only as a linguistic unit, but also as an expression of sociocultural phenomena. Emporonyms are characterized by frequent changes, they are more mobile in comparison with other names of urban objects. According to the lexical and grammatical characteristic, it can be argued that all the significant parts of speech can act as the name of a trading institution. In addition to the identifying and differentiating functions, emporonyms carry out information and advertising functions. The study of the names of urban objects, including emoronyms, allows us to answer many questions of onomastic phenomena, both in diachrony and synchrony. In onomastics, anthropocentrism is clearly expressed; this provision is also characteristic of store names. The formation of urbanonyms derived from anthroponyms in many cases connected with this process.

Keywords: Bashkir language, onomastics, urbanonym, emporonym, nomination.

Published in Russian. Do not hesitate to contact us at bulletin_bsu@mail.ru if you need translation of the article.

\section{REFERENCES}

1. Alfis Gayazov, Gulfira Abdullina, Flyuza Fatkullina, Guzaliya Ilyasova. Pan-Turkic ergonyms as a linguocultural and socio-cultural phenomenon of the Republic of Bashkortostan. Advances in Engineering Research, volume 191. Pp. 66-69.

2. Karabaev M. I., Abdullina G. R., Ishkildina Z. K. Mediterranean journal of social sciences. Rome-Italy, MCSER Publishing. 2015. Vol. 6. No. 3 S3. May. Pp. 73-82.

3. Tektigul Zh. O., Sadirova K. K., Kussanova B. N., Zhuminova A. B., Shetiyeva A. T. and Karabaev M. I. Modern Journal of Language Teaching Methods, Vol. 7, Issue 11, November. 2017. Rr.185-191.

4. Asanov A. Yu. Urbanonimiya goroda Tambova v lingvokognitivnom aspekte: diss. ... kand. filol. nauk. Tambov, 2014.

5. Abdullina G. R., Abdullina L. B., Sultanova M. R. Sovremennye problemy prepodavaniya bashkirskogo yazyka kak rodnogo i gosudarstvennogo v Respublike Bashkortostan i drugikh regionakh Rossiiskoi Federatsii: mat-ly IV Vserossiiskoi (s mezhdunar. uchastiem) nauchno-metod. konf., posvyashchennoi 100-letiyu obrazovaniya Bashkirskoi ASSR i 110-letiyu Bashkirskogo gosudarstvennogo universiteta (g. Ufa, 15 fevralya 2019 g.). Ufa: RITs BashGU, 2019. Pp. 5-9.

6. Bondaletov V. D. Russkaya onomastika [Russian onomastics]. Moscow: Prosveshchenie, 1983.

7. Golomidova M. V. Iskusstvennaya nominatsiya v onomastike [Artificial nomination in onomastics]. Ekaterinburg, 1998.

8. Dolganova A. Yu. Vestnik Udmurt-skogo un-ta. Filol. nauki. 2006. No. 5(2). Pp. 25.

9. Kachalkova Yu. A. Voprosy onomastiki. 2013. No. 1. Pp. 88-103.

10. Kadolo T. A. Izvestiya Saratovskogo universiteta. Ser. Filologiya. Zhurnalistika. 2015. No. 3.

11. Karabaev M. I. Bashкоrt onomastikahy: икуи киllanmahy. Өfө: BDU, 2015.

12. Podol'skaya N. V. Slovar' russkoi onomasticheskoi terminologii. 2 ed., pererab. i dop. [Dictionary of Russian onomastic terminology. 2nd Ed., rev. and ext.]. Moscow: Nauka, 1988.

13. Razumov R. V. Voprosy onomastiki. 2010. No. 2(9). Pp. 95-100.

14. Razumov R. V. Verkhnevolzhskii filol. vestnik. 2015. No. 2. Pp. 14-19.

15. Romanova T. P. Vestnik Samarskogo gos. un-ta. Ser. «Filologiya» M. 2008. No. 1.

16. Romanova T. P. Vestnik Samarskogo gos. un-ta. Ser. «Filologiya». 1998. No. 1.

17. Sologub O. Vestnik Tomskogo gos. un-ta, 2009. No. 3(7). Pp. 51. 
18. Superanskaya A. V. Obshchaya teoriya imeni sobstvennogo [General theory of proper name]. Moscow: Nauka, 1973.

19. Fazylova G. R., Abdullina G. R. Vestnik BashGU. 2019. Vol. 24. No. 1. Pp. 155-158. DOI: https://doi.org/10.33184/bulletin-bsu2019.1.26.

20. Fazylova G. R., Karabaev M. I. Vestnik BashGU. 2019. Vol. 24. No. 4. DOI: https://doi.org/10.33184/bulletin-bsu-2019.4.36.

21. Fazylova G. R. Innovatsionnaya nauka. Ufa, 2016. No. 4. Pt. 4. Pp. 110-112.

22. Shmeleva T. V. Onomastika: uchebnoe posobie [Onomastics: textbook]. Slavyansk-na-Kubani: Izdatel'skii tsentr filiala FGBOU VPO «KubGU», 2013.

23. Shmeleva T. V. Yazyk goroda. Naimenovaniya magazinov [Urban language. Shop names]. Krasnoyarsk: Krasnoyarskii un-t, 1989.

Received 30.04.2020. 